\title{
Blood testing compared with urine testing in the long term control of diabetes
}

\author{
P F W MILLER, C STRATTON, AND J H TRIPP \\ Department of Paediatrics, Royal Devon and Exeter Hospital and Department of Psychology, \\ University of Exeter
}

SUMMARY A comparison of visually read glucose oxidase strips and urine testing is reported in an unselected group of 19 diabetic children in relation to the degree of control achieved and to its acceptability. The degree of control was at least as good after five months' blood glucose monitoring at home (mean blood glucose $9.3 \pm$ SEM $2.9 \mathrm{mmol} / \mathrm{l}$, mean 24 hour glucose excretion $113 \pm$ SEM $168 \mathrm{mmol} / \mathrm{l}$ ) as after five months' urine testing (mean blood glucose $11 \cdot 1 \pm \mathrm{SEM} 4 \cdot 1 \mathrm{mmol} / \mathrm{l}$, mean 24 hour glucose excretion $141 \pm$ SEM $98 \mathrm{mmol} / \mathrm{l}$ ). Home blood glucose monitoring was preferred either alone or in conjunction with urine testing in most cases.

It is becoming clearer that the long term complications of diabetes mellitus are related to the degree of control achieved ${ }^{1}$ and that in adults this can be improved by regular home monitoring of blood glucose estimations. ${ }^{2} 3 \mathrm{~A}$ recent review article advocated the use of such monitoring in children, ${ }^{4}$ but no long term controlled studies comparing blood with urine monitoring in relation to the degree of control possible or the acceptability of this technique have been reported. Most surveys of home blood glucose monitoring have used reflectance meters, but this has been questioned on grounds of expense, clumsiness, and because they may induce a false sense of accuracy. ${ }^{56}$ We did a crossover trial in children to compare the accuracy and acceptability of conventional urine testing with home blood glucose monitoring, without the use of reflectance meters.

\section{Methods}

Twenty five diabetic children between the ages of 8 and 15 (median 13) years attending paediatric outpatient clinics at the Royal Devon and Exeter Hospital were asked to take part in the trial for a 10 month period. They were selected from the hospital diagnostic index on the basis of age and convenient access to the centre for monthly follow up. Four of these did not wish to take part in the trial: one was already on blood glucose testing and was not prepared to revert to urine testing for five months; one was not prepared to carry out any form of regular testing; one, a girl of 8 years, was frightened

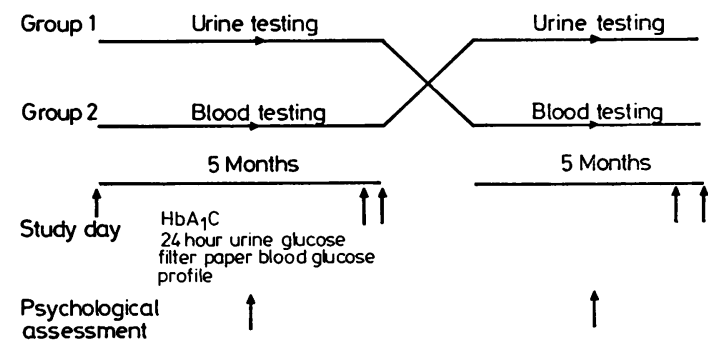

Figure Design of trial.

of the idea; and one had recently started on twice daily insulin and was not prepared to accept yet more needles. Two patients were excluded; one because at the start of the trial she was having frequent hypoglycaemic attacks, and another because she was in the 'honeymoon' phase of her diabetes. The design of the trial is outlined in the Figure. All testing was carried out in the patient's home.

Patients were randomly allocated to an initial period of five months' blood or urine testing, followed by a similar period on the alternative form of testing. At the start of the trial each child and his or her parents were given a short talk about the nature of diabetes, the importance of diabetic control, and the technique of blood testing. At the beginning of blood glucose testing they were encouraged to continue with urine testing as well for about a week to gain confidence in the new tests. The children were taught to take blood from the radial aspect of the index finger (to reduce the pain associated with pin 
pricks in the finger tips) using an Autolet blood sampling device. Blood glucose was estimated twice each day using Dextrostix and making a comparison with the colour code on the side of the bottle. Patients were asked to vary the timing of the tests, but always to measure them before meals and record their results on a graph, so that over a month a glucose profile would be obtained. Urine was tested in the conventional way twice a day and double micturition was encouraged. Patients were seen monthly throughout the trial in the paediatric outpatient clinics, on the wards after school, or in their own homes.

Dosages and on four occasions types of insulin were changed as indicated by the previous month's results. and dietary advice was given. The degree of control achieved was assessed on study days, at the beginning, and twice at the end of each form of testing by the measurement of a filter paper glucose profile, 24 hour urine glucose excretions, and glycosylated haemoglobin concentrations. The children's attitude to testing was assessed by a structured interview carried out by CS on two occasions-once on each form of testing. The interviews, usually carried out with a parent present after consent had been given, were recorded on tape for subsequent analysis. The study was approved by the health district ethical committee.

\section{Results}

Of the 19 patients one only-an 11 year old boy of borderline subnormal intelligence who attends a school for delicate children-did not complete the trial. He failed to carry out the study day tests, but is now using home blood glucose testing by choice and achieving very good control as a result. During the trial one patient required admission for ketoacidosis precipitated by an attack of tonsillitis.

\section{Assessment of control}

The results of the study day tests are shown in the Table. In the pre-project assessment the 2 groups of patients are comparable. At the end of the project all the parameters were reduced and since none of the patients had appreciable hypoglycaemia this suggests an improvement in control. The greatest mean improvements in the parameters occurred after 5 months of blood testing. None of these changes achieved statistical significance at the $P<0.05$ level though the improvements in the mean blood glucose values and the urine glucose concentrations approached this.

Very marked changes in diabetic control were noted in response to social problems such as the impending parental separation in two children and the detection of a breast lump in the mother of another. The degree of motivation of the children in the group was variable; the better motivated patients achieved better control. Two children had low renal thresholds for glucose and as expected they benefited greatly from blood monitoring.

\section{Assessment of acceptability}

Overall preference. The patients were asked which type of testing they preferred; 16 preferred blood testing alone, none preferred urine testing alone, and two preferred a mixture of the two.

Reasons for preference. Many found the new technique easier to carry out and 8 mentioned that they felt more in control of their diabetes. The ability to carry out spot checks of their blood glucose concentrations was particularly useful in cases of nocturnal hypoglycaemia-a Dextrostix before bed could either reassure or indicate the need for further carbohydrate.

Disadvantages of blood monitoring. Twelve children found difficulty in obtaining blood samples, and 7

Table Means of profile measurements in different phases of the project with mean changes and standard error of the mean (SEM; $x \pm y$ )

\begin{tabular}{|c|c|c|c|c|c|c|c|c|}
\hline & \multicolumn{4}{|c|}{ Phase I pre-project to first monitoring } & \multicolumn{4}{|c|}{ Phase 2 first monitoring to second monitoring } \\
\hline & \multicolumn{2}{|c|}{ Group 1} & \multicolumn{2}{|c|}{ Group 2} & \multicolumn{2}{|l|}{ Group 1} & \multicolumn{2}{|l|}{ Group 2} \\
\hline & $\begin{array}{l}\text { Pre- } \\
\text { project }\end{array}$ & $\begin{array}{l}\text { After } \\
5 \text { months' } \\
\text { urine } \\
\text { testing }\end{array}$ & $\begin{array}{l}\text { Pre- } \\
\text { proiert }\end{array}$ & $\begin{array}{l}\text { After } \\
5 \text { months' } \\
\text { blood } \\
\text { testing }\end{array}$ & $\begin{array}{l}\text { After } \\
5 \text { months' } \\
\text { urine } \\
\text { testing }\end{array}$ & $\begin{array}{l}\text { After } \\
5 \text { months' } \\
\text { blood } \\
\text { testing }\end{array}$ & $\begin{array}{l}\text { After } \\
5 \text { months' } \\
\text { blood } \\
\text { testing }\end{array}$ & $\begin{array}{l}\text { After } \\
5 \text { months' } \\
\text { urine } \\
\text { testing }\end{array}$ \\
\hline \multirow{5}{*}{$\begin{array}{l}\text { Mean of filter paper glucose profile }(\mathrm{mmol} / \mathrm{l}) \\
\text { Mean change } \pm \text { SEM } \\
24 \text { hour urine glucose }(\mathrm{mmol} / \mathrm{l}) \\
\text { Mean change } \pm \text { SEM } \\
\text { Glycosylated haemoglobin } \mathrm{HbA}_{1 \mathrm{c}} \mathrm{g} / \mathrm{dl} \\
\text { Mean change } \pm \mathrm{SEM}\end{array}$} & $12 \cdot 6$ & $11 \cdot 4$ & $12 \cdot 3$ & $9 \cdot 6$ & \multirow{2}{*}{\multicolumn{2}{|c|}{$\begin{array}{c}11 \cdot 4 \\
-2 \cdot 4 \pm 3 \cdot 1\end{array}$}} & \multirow{2}{*}{\multicolumn{2}{|c|}{$\begin{array}{c}9.610 .8 \\
1 \cdot 2 \pm 3 \cdot 8^{10.8}\end{array}$}} \\
\hline & \multicolumn{2}{|c|}{$-1 \cdot 2 \pm 4 \cdot 5$} & \multicolumn{2}{|c|}{$-2 \cdot 7 \pm 2.6$} & & & & \\
\hline & 173 & 172 & 231 & 112 & & 114 & 112 & 109 \\
\hline & \multicolumn{2}{|c|}{$-1 \pm 107$} & \multicolumn{2}{|c|}{$119 \pm 229$} & \multicolumn{2}{|c|}{$58 \pm 117$} & \multicolumn{2}{|c|}{$-3 \pm 94$} \\
\hline & $\begin{array}{r}11 \cdot 0 \\
-0 .\end{array}$ & $2 \cdot 3^{10 \cdot 5}$ & $\begin{array}{r}11 \cdot 2 \\
-0 .\end{array}$ & $1 \cdot 3^{10 \cdot 4}$ & $\begin{array}{r}10 \cdot 5 \\
0 \cdot(\end{array}$ & $10 \cdot 5$ & $\begin{array}{l}10.4 \\
0.8 \pm\end{array}$ & $2 \cdot 0^{11 \cdot 0}$ \\
\hline
\end{tabular}

Conversion: SI to traditional units-Blood glucose: $1 \mathrm{mmol} / 1 \approx 18 \mathrm{mg} / 100 \mathrm{ml}$. 
complained of sore fingers. Patients often used sites other than their index fingers but with time this became less of a problem. Only 4 had difficulty in interpreting the colour of the Dextrostix but this could be overcome by the use of a meter.

\section{Post-trial assessment}

At the end of the trial the patients were asked which form of testing they would like to continue-7 wanted to continue with blood testing alone, 2 wanted to continue with urine testing alone, and 9 wanted to continue with a combination of the two methods. They have broadly followed this pattern at recent follow up.

\section{Discussion}

Evidence that the degree of diabetic control is related to the long term microvascular complications has been shown by Tchbroutsky. ${ }^{1}$ If one accepts this, diabetic children, in view of their longer exposure to the disease, are the most likely to benefit from tight control. These children are often difficult to control because of their variable energy expenditure, dietary indiscretions, changes in insulin requirements in relation to growth, and the emotional problems of adolescence. It is a clinical observation that children find urine testıng unpleasant and tedious.

Walford $e t$ al. ${ }^{2}$ and Sonksen $e t a l^{3}$ produced evidence which suggested that in adults home glucose monitoring could allow better control and that patients often preferred this form of testing, but these trials were retrospective and lacked controls. The results of a controlled trial in a well motivated group of pregnant women concluded that there might be a place for blood monitoring in some patients. ${ }^{7}$ Control was not improved with blood monitoring and with adequate attention to detail extremely good results could be achieved with urine testing. These trials all used reflectance meters, but an assessment of the patients' accuracy in reading Dextrostix showed that this method compared well with laboratory glucose analyses. ${ }^{6}$ In this study the possibility of machine error was also recognised. Machines are sensitive to the minor abuses to be expected in the home, and this problem, combined with their price ( $£ 70$ minimum) and inconvenience, prompted us to investigate the possibility of home blood glucose monitoring without meters.

Test to test variation in the day to day measurement of blood glucose concentrations is often large and one needs to know whether an individual value is high, low, or about right. The results of this trial suggest that home blood glucose monitoring with visually read Dextrostix may lead to better control of diabetes in some patients. The good results achieved in this group are comparable to those achieved in other series of closely supervised diabetics, ${ }^{8}{ }^{9}$ suggesting that any further improvement with the use of meters would be small, and it is doubtful whether the expense could be justified.

The results of the attitude testing were contrary to the expectations of many of the doctors looking after the children, since all the children preferred blood testing either alone or in combination to urine testing alone. After the trial the majority continued with blood testing at least some of the time. Blood testing was especially useful on holidays, in the early morning rush before school, and when control was in doubt. A notable feature during the trial was the improvement in the patients' understanding of their disease.

The effectiveness of any system to improve diabetic control depends on several factors; the skill of the doctor to advise on its use, the ability and motivation of the patient in using the technique, and the attention paid to dietary advice and insulin administration. We suggest that blood monitoring is an aid to diabetic control, and that young diabetics should be instructed in blood and urine monitoring and be allowed to use either or both. This approach should lead to a greater number of young diabetics finding tight control easier to achieve and result in a reduction in the prevalence of microvascular complications.

\section{References}

1 Tchbroutsky G. Relation of diabetic control to development of microvascular complications. Diabetologia 1978; 15: $143-52$.

2 Walford S, Gale E A M, Allison S P, Tattersall R B. Self monitoring of blood glucose. Lancet 1978; i: 732-5.

${ }^{3}$ Sonksen P H, Judd S K, Lowy C. Home monitoring of blood glucose. Lancet 1978; i: 729-32.

4 Baum J D. Home monitoring of diabetic control. Arch Dis Child 1981; 56: 897-9.

5 Anonymous. Home blood glucose monitoring: revolution, revelation, or rip-off? Lancet 1980; ii: 187-8.

6 Steel J M, Cramb R, Duncan L J P. How useful are patient-operated blood glucose meters? Practitioner 1980; 224: 651-3.

7 Stubbs S M, Brudenell J M, Pyke D A, Watkins P J, Stubbs W A, Alberti K G M M. Management of the pregnant diabetic: home or hospital, with or without glucose meters? Lancet 1980 ; i: 1122-4.

8 Langdon D R, James F D, Sperling M A. Comparison of single- and split-dose insulin regimens with 24 hour monitoring. J Pediatr 1981; 99: 854-61.

9 Mann N P, Johnston D I. Total glycosylated haemoglobin $\left(\mathrm{Hb} \mathrm{A}_{1}\right)$ levels in diabetic children. Arch Dis Child 1982; 57: 434-7.

Correspondence to Dr $\mathbf{P}$ Miller, Department of Paediatrics \& Child Health, St James's University Hospital, Beckett Street, Leeds LS9 7TF.

Received 11 January 1983 